\title{
Use of annulus washer after debridement: A new mitral valve replacement technique for patients with severe mitral annular calcification
}

\author{
Syed Tarique Hussain, MD, ${ }^{\mathrm{a}}$ Jahanzaib Idrees, MD, ${ }^{\mathrm{a}}$ Nicholas A. Brozzi, MD, ${ }^{\mathrm{a}}$ \\ Eugene H. Blackstone, MD, ${ }^{\mathrm{a}, \mathrm{b}}$ and Gösta B. Pettersson, MD, PhD, ${ }^{\mathrm{a}}$ Cleveland, Ohio
}

Extreme calcification of the mitral annulus (MAC) is a formidable challenge during mitral valve surgery, with the risk of serious and potentially fatal complications such as stroke, atrioventricular disruption, ventricular rupture, valve dehiscence, and periprosthetic leakage. ${ }^{1}$ A variety of surgical techniques have been developed that vary from avoiding or minimizing any decalcification ${ }^{2}$ to extensive radical removal of the calcium bar followed by reconstruction of the atrioventricular annulus. ${ }^{3-5}$ We describe our experience with an intermediate approach that involves limited debridement of the calcified annulus, allowing implantation of a good-sized prosthesis using a felt washer, sandwiched between the annulus and prosthesis, as a support.

\section{PATIENTS AND METHODS}

From August 2006 to October 2011, 20 patients with severe MAC underwent mitral valve replacement using the polytetrafluoroethylene (PTFE) washer technique for symptomatic native mitral valve disease $(\mathrm{n}=17)$, periprosthetic leakage $(\mathrm{n}=2)$, and systolic anterior motion of the anterior mitral valve leaflet after myectomy $(\mathrm{n}=1)$. Mean age was $75 \pm 18$ years (range, 51-87 years). Eleven patients predominantly had regurgitation, 5 had stenosis, and 4 had both. Thirty-one concomitant procedures were performed in 20 patients (Table 1). The study was approved by the Institutional Review Board of the Cleveland Clinic, with patient consent waived.

\section{Operative Technique}

Conventional full median sternotomy, standard cannulation (except in 1 patient in whom the axillary artery was cannulated because of extensive

\footnotetext{
From the Department of Thoracic and Cardiovascular Surgery, ${ }^{\mathrm{a}}$ Heart and Vascular Institute, and the Department of Quantitative Health Sciences, ${ }^{b}$ Research Institute, Cleveland Clinic, Cleveland, Ohio.

This study was supported in part by the Kenneth Gee and Paula Shaw, $\mathrm{PhD}$, Chair in Heart Research (to E.H.B.), and the Peter and Elizabeth C. Tower and Family Endowed Chair in Cardiothoracic Research, James and Sharon Kennedy, the Slosburg Family Charitable Trust, Stephen and Saundra Spencer, and Martin Nielsen (to G.B.P.).

Disclosures: Authors have nothing to disclose with regard to commercial support.

Read at the AATS Mitral Conclave 2013, New York, NY, May 2-3, 2013.

Received for publication Oct 2, 2012; accepted for publication Dec 11, 2012.

Address for reprints: Gösta B. Pettersson, MD, PhD, Department of Thoracic and Cardiovascular Surgery, Cleveland Clinic, 9500 Euclid Ave/Mail Stop J4-1, Cleveland, OH 44195 (E-mail: petterg@ccf.org)

J Thorac Cardiovasc Surg 2013;145:1672-4

$0022-5223 / \$ 36.00$

Copyright $(2) 2013$ by The American Association for Thoracic Surgery

http://dx.doi.org/10.1016/j.jtcvs.2012.12.049
}

aortic calcification), and normothermic cardiopulmonary bypass were used in all patients.

The mitral valve is approached transeptally. First the severity of the disease and valvular dysfunction is reevaluated to finalize the surgical plan. This includes sizing the valve opening and estimating the debridement necessary to implant a good-sized valve. Exposure is optimized with a low threshold to extend the atrial septal incision to the dome of the left atrium and add a proximal aortotomy. The anterior leaflet is preserved and transposed posteriorly to support the annulus, and when doable, the posterior leaflet is released and also salvaged for support. Debridement is performed carefully piece by piece by rongeur, often using a dual approach from the left atrium and aortic root. Great care is taken to avoid transmural defects in the atrioventricular groove or deep defects in the posterior wall muscle. Size and shape of the mitral opening are repeatedly reevaluated until it is deemed possible to place sutures and implant a prosthesis of good size. In some cases this requires extensive debridement. The valve sutures are placed through or around the residual calcium and annulus, with pledgets on the ventricular side (Figure 1, A). Working through the aortotomy often allows better placement of valve sutures in the region of the central fibrous body. A $1-$ to $1.5-\mathrm{cm}$ wide $(1 / 2$ inch) PTFE felt washer is inserted in between the annulus and sewing ring of the prosthesis from trigone to trigone posteriorly (Figure 1,B). The valve and the washer are tied down. The washer is then sutured to the atrial wall with a second suture line using running No. 4-0 polypropylene (Figure 1,C). Generous irrigation is performed repeatedly to clear the heart of loose pieces of calcium.

\section{RESULTS}

Mean implanted valve size was $27 \mathrm{~mm}$ (range, 23-31 $\mathrm{mm}$; Table 1). Predischarge mitral prosthetic gradient was $5.0 \pm 3.0 \mathrm{~mm} \mathrm{Hg}$. At a mean follow-up of 8 months (range, 2-60 months), there were no periprosthetic leaks or valverelated reinterventions. One hospital death occurred after 60 days as a result of multisystem organ failure and sepsis in a renal transplant patient with preexisting severe pulmonary hypertension. One patient required reexploration for chest wall bleeding, and 2 had transient neurologic deficits. Actuarial survival was $50 \%$ at 5 years, with 5 late noncardiac deaths.

\section{DISCUSSION}

Current techniques described in the literature ${ }^{2-5}$ involve either extensive calcium debridement and annular reconstruction, risking ventricular rupture and bleeding, or a conservative approach and use of a small-sized prosthesis, at the risk of periprosthetic leakage. Our technique is designed to allow implantation of a good-sized prosthesis 
TABLE 1. Preoperative patient characteristics and operative details $(\mathbf{n}=\mathbf{2 0})$

\begin{tabular}{|c|c|}
\hline Variable & No. \\
\hline \multicolumn{2}{|l|}{ Patient characteristics } \\
\hline \multicolumn{2}{|l|}{ Demography } \\
\hline Age $(y)$, mean $\pm S D$ & $75 \pm 18$ \\
\hline Female & 15 \\
\hline \multicolumn{2}{|l|}{ Mitral valve disease } \\
\hline Degenerative & 10 \\
\hline Hypercalcemia, after renal transplant & 2 \\
\hline After radiation & 2 \\
\hline Periprosthetic leakage & 2 \\
\hline HOCM/SAM & 2 \\
\hline Rheumatic heart disease & 2 \\
\hline \multicolumn{2}{|l|}{ Comorbidities } \\
\hline Hypertension & 15 \\
\hline Coronary artery disease & 10 \\
\hline Prior CABG & 3 \\
\hline Renal insufficiency & 7 \\
\hline Diabetes mellitus & 5 \\
\hline \multicolumn{2}{|l|}{ History of cardiac operations } \\
\hline Prior cardiac operation & 8 \\
\hline Reoperation & 8 \\
\hline 1 & 4 \\
\hline 2 & 3 \\
\hline 3 & 1 \\
\hline Prior mitral valve replacement & 2 \\
\hline \multicolumn{2}{|l|}{ Operative details } \\
\hline \multicolumn{2}{|l|}{ Prosthetic valve type and size } \\
\hline Bioprosthetic tissue valve & 18 \\
\hline No. 25 & 4 \\
\hline No. 27 & 6 \\
\hline No. 29 & 7 \\
\hline No. 31 & 1 \\
\hline Mechanical valve & 2 \\
\hline No. 23 & 1 \\
\hline No. 31 & 1 \\
\hline Concomitant procedures & 31 \\
\hline Aortic valve replacement & 10 \\
\hline Aortic valve repair & 1 \\
\hline CABG & 6 \\
\hline Tricuspid valve repair & 5 \\
\hline Aortic root replacement & 3 \\
\hline Maze procedure & 3 \\
\hline Myectomy & 3 \\
\hline
\end{tabular}

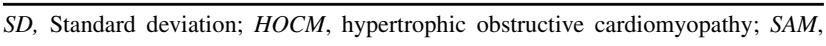
systolic anterior motion; $C A B G$, coronary artery bypass grafting.

with low risk of ventricular rupture and periprosthetic leak. Risk of ventricular rupture is minimized by debriding only enough calcium to make room for the prosthesis, leaving some calcium and the capsule posteriorly. Sandwiching a PTFE felt washer between the valve ring and annulus offers additional support, and its attachment to the atrium with a running suture provides a good seal, decreasing risk of periprosthetic leakage. The dual approach, working through the atrium and the aortic valve, is very helpful.
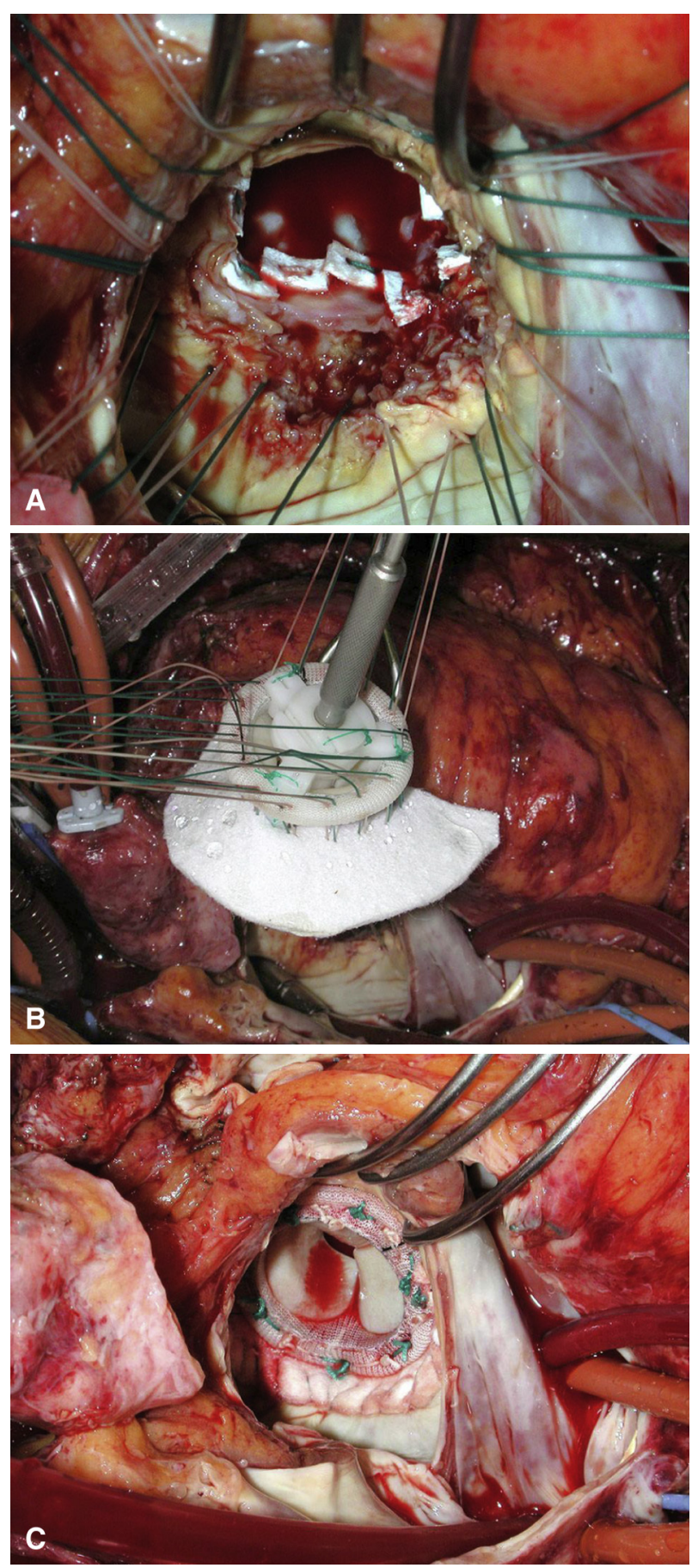

FIGURE 1. Technique for mitral valve replacement in patients with severe mitral annulus calcification. A, Appearance of posterior mitral valve annulus after limited calcium debridement and placement of pledget-supported sutures around and through residual calcium. B, Felt washer sandwiched between the annulus and sewing ring of the prosthesis. C, Final appearance: The prosthesis is tied down, and the felt washer is sutured to the atrial wall.

This approach, with limited calcium debridement and use of a sandwiched felt washer, is a new, easier, and possibly safer way to implant an acceptably sized mitral prosthesis in patients with severe MAC. 


\section{References}

1. Cammack Pl, Edie RN, Edmunds LH Jr. Bar calcification of the mitral annulus: a risk factor in mitral valve operations. J Thorac Cardiovasc Surg. 1987;94: 399-404.

2. Grossi EA, Galloway AC, Steinberg BM, Leboutillier M III, Delianides J, Baumann FG, et al. Severe calcification does not affect long-term outcome of mitral valve repair. Ann Thorac Surg. 1994;58:685-8.
3. Carpentier AF, Pellerin M, Fuzellier JF, Relland JY. Extensive calcification of the mitral valve annulus: pathology and surgical management. J Thorac Cardiovasc Surg. 1996;111:718-30.

4. David TE, Feindel CM, Armstrong S, Sun Z. Reconstruction of the mitral annulus: a ten-year experience. J Thorac Cardiovasc Surg. 1995;110:1323-32.

5. Feindel CM, Tufail Z, David TE, Ivanov J, Armstrong S. Mitral valve surgery in patients with extensive calcification of the mitral annulus. $J$ Thorac Cardiovasc Surg. 2003;126:777-82.

\title{
Use of a polytetrafluoroethylene graft to prevent recurrence of saphenous vein graft aneurysm after coronary artery bypass grafting
}

\author{
Syed T. Hussain, MD, Nicholas G. Smedira, MD, and Eric E. Roselli, MD, Cleveland, Ohio
}

Dilatation of vein grafts occurs in $14 \%$ of patients within 14 years after coronary artery bypass grafting (CABG), but is rarely of concern. ${ }^{1}$ Saphenous vein graft (SVG) aneurysm (SVGA), however, is a potentially fatal complication. ${ }^{2,3}$ In a recent retrospective analysis, only 16 patients underwent surgical repair of SVGAs during a 30-year interval in which 28,603 patients underwent CABG. ${ }^{4}$ Recurrence of SVGA after reoperation is unknown. Theoretically, the risk remains, because the conditions for development of this complication are unchanged. We describe a novel technique with a polytetrafluoroethylene graft to encapsulate the new vein graft and avoid late aneurysmal degeneration.

\section{CLINICAL SUMMARY}

A 66-year-old man underwent CABG in 1993, with separate SVGs to the obtuse marginal artery $(\mathrm{OM})$ and the posterior descending artery (PDA) and a left internal thoracic artery graft to the left anterior descending coronary artery. He had a history of bilateral popliteal artery aneurysms that were stented. Twelve years after this operation, during a workup for dizziness, he had a coronary angiogram that showed aneurysmal dilatation of his vein grafts. He was started on warfarin, and no other intervention was performed. He came to us 5 years later with new, recurring substernal chest pain. A repeated coronary angiogram showed a dilated yet patent vein graft to the OM. The right graft could not be engaged during the angiogram. Computed

From the Department of Thoracic and Cardiovascular Surgery, Heart and Vascular Institute, Cleveland Clinic, Cleveland, Ohio.

Disclosures: Authors have nothing to disclose with regard to commercial support.

Received for publication Jan 31, 2013; accepted for publication Feb 13, 2013; available ahead of print March 8, 2013.

Address for reprints: Eric E. Roselli, MD, Cleveland Clinic, Department of Thoracic and Cardiovascular Surgery, 9500 Euclid Ave, Desk J4-1, Cleveland, OH 44195 (E-mail: roselle@ccf.org).

J Thorac Cardiovasc Surg 2013;145:1674-5

$0022-5223 / \$ 36.00$

Copyright (c) 2013 by The American Association for Thoracic Surgery

http://dx.doi.org/10.1016/j.jtcvs.2013.02.033 tomography of the chest showed diffuse aneurysms of both the OM and PDA vein grafts, with maximum diameters of 3.1 and $5 \mathrm{~cm}$, respectively (Figure 1).
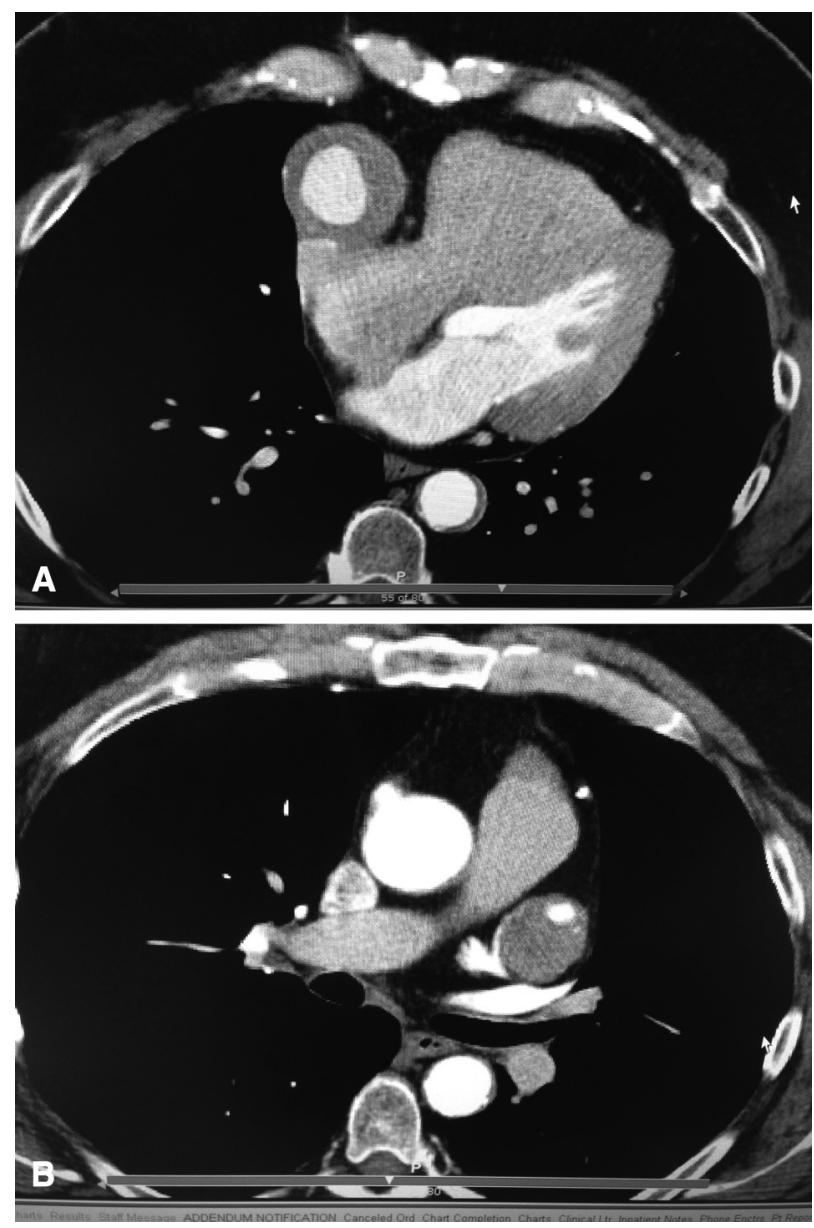

FIGURE 1. Preoperative computed tomographic scan showing large pseudoaneurysm of saphenous vein graft to the right coronary artery (A) and to the obtuse marginal artery (B). 